Sharif University of Technology
Scientia Iranica
SCIENTIA
IRAN ICAA

\title{
Evaluating the nature of captured exhaust soot from a retort heating carbonization system
}

\author{
A.G. Adeniyi ${ }^{a, *}$, D.V. Onifade ${ }^{a}$, and J.O. Ighalo ${ }^{a, b}$ \\ a. Department of Chemical Engineering, Faculty of Engineering and Technology, University of Ilorin, Ilorin, P. M. B. 1515, \\ Nigeria. \\ b. Department of Chemical Engineering, Nnamdi Azikiwe University, P. M. B. 5025, Awka, Nigeria.
}

Received 18 October 2020; received in revised form 24 April 2021; accepted 2 August 2021

\section{KEYWORDS \\ Carbonisation; \\ Soot; \\ Char; \\ Characterisation; \\ Biomass.}

\begin{abstract}
A deeper understanding of all aspects of biomass thermochemical conversion is necessary as researchers pursue multiple avenues for energy and environmental sustainability. In this paper, the agglomerative accumulation of soot observed, captured on the inner surface of the exhaust pipe, during the operation of a top-lit updraft biomass carbonisation system was evaluated to understand its nature and qualities. The soot was evaluated using Fourier Transform Infrared Spectroscopy (FTIR), Scanning Electron Microscopy with Energy Dispersion Spectroscopy (SEM-EDS), and Brunauer-EmmettTeller (BET) analyses. The combustion fuels were bamboo (Bambusa vulgaris) stalk and stem of African balsam (Daniellia olivieri). FTIR analysis revealed the presence of hydroxyl, aromatic double bond, aldehyde, thyiol, and carbonyl functional groups. Energy Dispersion Spectroscopy (EDS) analysis revealed that the elemental carbon content of the soot was found to be $75.05 \%$ carbon with $15.13 \%$ oxygen. Scanning Electron Microscopy (SEM) analysis showed that the soot had a hollow morphology and a lustrous appearance with white tiny grit grains of carbon nano-spheres. The BET analysis revealed that the specific surface area of the soot was $500 \mathrm{~m}^{2} / \mathrm{g}$, while the pore volume and pore diameter were measured to be $0.218 \mathrm{cc} / \mathrm{g}$ and $2.113 \mathrm{~nm}$, respectively. The material can find use in water purification purposes and also, as an additive to lubricating oils.
\end{abstract}

(C) 2022 Sharif University of Technology. All rights reserved.

\section{Introduction}

Thermochemical processing is an established technique of biomass valorization [1]. Such thermochemical processes include pyrolysis, gasification, combustion, hydro-thermal carbonisation, and torrefaction [2,3]. Gasification is one of the most popular techniques and it has been investigated for numerous feedstocks over

\footnotetext{
*. Corresponding author.

E-mail address: adeniyi.ag@unilorin.edu.ng (A.G. Adeniyi)
}

doi: $10.24200 /$ sci. 2021.57008 .5017 the years $[4,5]$. The types of thermochemical conversion reactors include fixed bed, fluidized bed, ablative reactors, rotating cones, kilns, and furnaces [6,7]. Operation mode can be batch, semi-batch, and continuous [6].

For gasification reactors, a stream of inlet air is essential to the process. Fluidized bed gasifiers are fluidized by the inlet air stream by either circulation or bobbling [8], while fixed bed reactors have lower air velocity and are non-suspended in the inlet fluid. The inlet air-flow for the fixed bed takes three basic configurations: updraft [9], downdraft [10-13], and cross-draft [8]. Reactors can also be top-lit or bottom- 
lit based on the point of ignition of the combustion fuel [9]. Recent studies have utilized a low-temperature biochar-optimized carbonizer design in which an outer combustion space generates heating for the inner carbonization chamber. It has been evaluated for biochar production from elephant grass [14,15], plantain fibres [16], orange peel and albedo [17], almond leaves [18], sugarcane bagasse [19], and oil palm fibre [20]. In such hybrid systems where combustion is involved, soot is also produced and trapped.

Several studies have attempted to gain an understanding of combustion soot, albeit for vehicular combustion engines [21-23], domestic stoves [24], and various oxidation-gasification systems [25-27]. Some thermochemical conversion systems do not produce soot as their reaction does not involve combustion and flame. However, the current design under consideration $[14,16]$ generates thermal energy for carbonization from an outer combustion region of which exhaust fumes are released. A significant agglomerative accumulation of fine soot char was observed to be trapped in the inner sections of the exhaust.

In this paper, the soot noticed from the experimentations in Adeniyi et al. [14,16] was evaluated to understand its nature and qualities with suggested possible application. The captured soot was evaluated using Fourier Transform Infrared Spectroscopy (FTIR), Scanning Electron Microscopy with Energy Dispersion Spectroscopy (SEM-EDS), and BranueurEmmett-Teller (BET) analyses.

\section{Methodology}

\subsection{Experimental}

The sizing and design, operational considerations, and yield of products for the top-lit updraft biomass carbonizer with retort heating have been discussed elsewhere [14,16]. However, the soot is formed by the agglomerative accumulation of the fumes of the combustion fuels trapped and captured onto the inner walls of the exhaust pipe. The combustion fuels were bamboo (Bambusa vulgaris) stalk and stem of African balsam (Daniellia olivieri). The soot was retrieved from the exhaust pipe using a spatula and placed within sample bottles for analysis. The samples were employed in two carbonization runs individually for biochar production from elephant grass by Adeniyi et al. [14] and from plantain fibres by Adeniyi et al. [16]. Since the same combustion fuel (bamboo stalk and stem of African balsam) was used for retort heating, the soot in both studies was analyzed in this current investigation as it has been derived from the same parent material. The mechanisms of soot formation and methodologies for the characterization include FTIR, SEM-EDS, and BET analyses, to be discussed in the subsequent subsections.

\subsection{Fourier Transform Infrared Spectroscopy (FTIR)}

FTIR was conducted to determine the functional groups and complexes present in the soot char. The spectrophotometer model used for the FTIR analysis was SHIMADZU FTIR-8400S. The sample holder was cleaned using ethanol on wet wipes and care was exercised to prevent the splash or spill of the reagent on the equipment. On the user interphase, the scan range was set to $650-4500 \mathrm{~cm}^{-1}$. The sample was placed on the holder and then, scanned to obtain the spectrum.

\subsection{Scanning Electron Microscopy with Energy Dispersion Spectroscopy ( $S E M-E D S)$}

SEM was employed to examine the surface morphology of the soot char particles. A double adhesive was placed on the sample stub. The soot char was sprinkled on the stub and subsequently taken to a sputter coater (Quorum-Q150R Plus E) with $5 \mathrm{~nm}$ of gold. The stub was placed on a charge reduction sample holder and introduced into the column of the SEM machine (Phenom ProX by Phenom world Eindhoven Netherlands). It was initially viewed from a navigation camera (NavCam) before being sent to SEM mode. The spectrum was recorded using transmittance method in the $4000-650 \mathrm{~cm}^{-1}$ region with 30 scans. The acceleration voltage of the microscope was set to $15 \mathrm{kV}$ and magnification of 500 to 1500 times. Different magnifications were stored after adjustment of brightness and contrast.

\subsection{BET analysis}

BET analysis was used to study the particle and pore dimensional characteristics of the soot char. The surface area, pore volume, and sizes of the bio-char were measured using a BET analyzer (NOVA Station A). The surface properties of the soot were considered using multipoint BET surface area and DR (DubininRadushkevic) method for the pore volume and width (diameter), respectively. The bio-char was characterized by $\mathrm{N}_{2}$ adsorption test at $77 \mathrm{~K}$. A small amount of dry nitrogen gas was introduced to the sample tube to prevent contamination of the clean surface. The tube was then removed and the sample weighed. The tube was fixed to the volumetric apparatus; then, the sample was evacuated down to $2 \mathrm{~Pa}$ pressure. Adsorbate was introduced to give the lowest desired relative pressure; then, the adsorbed volume was measured.

\section{Results and discussion}

\subsection{The mechanism of the soot formation}

The general scheme of the formation of soot is illustrated in Figure 1. Controlled combustion occurred in the heating space (i.e., the combustion chamber) and the fumes produced are evacuated from the system via 


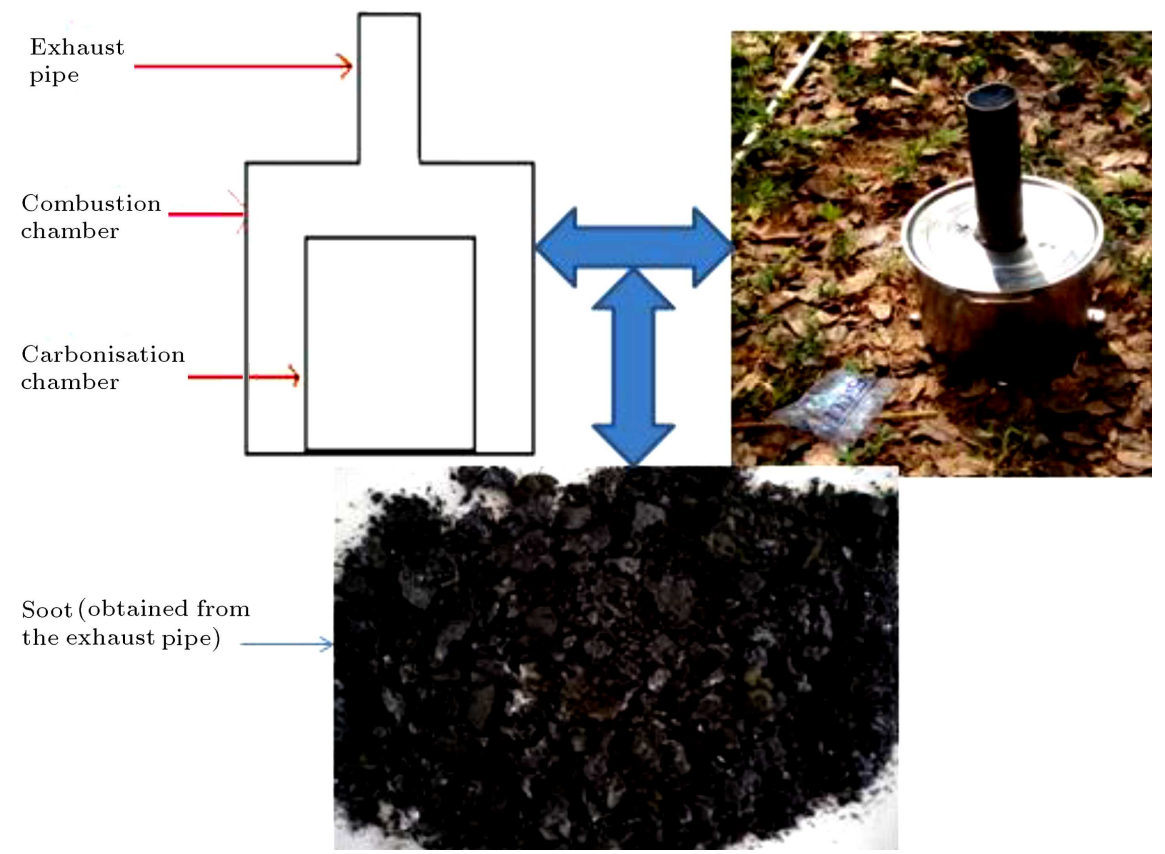

Figure 1. The general scheme of the process.

the exhaust pipe. The fumes go through the exhaust pipe; soot is captured on the inner rough surfaces. This zone in the exhaust pipe is of reduced geometry and is centrally located on top of the reactor. The ratio of exhaust pipe to that of the combustion chamber is $1: 10$. The key reaction of the coke formation is shown in Eq. (1):

$$
2 \mathrm{CO} \leftrightarrow \mathrm{C}+\mathrm{CO}_{2} .
$$

The coke deposition is induced by the conversion of carbon monoxide into carbon dioxide, especially in a system with limited oxygen (like that used in the study). This coke is the substance that agglomerates on precursors to form soot.

The transport of the produced smoke out of the combustion zone occurred between the space above the carbonisation chamber and the exhaust pipe through a reduced geometry. The formation of soot along the exhaust pipe diameter is enhanced by the reduced geometry. The interacting and consecutive steps involved include formation of soot precursors on the exhaust pipe, soot particle inception, and aggregation of soot particle, as shown in Figure 2. Once the precursors are formed, larger numbers of particles are produced along

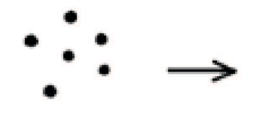

(a)

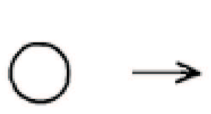

(b)

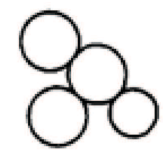

(c)
Figure 2. Formation mechanism of soot via soot precursors formation (a); soot particle inception (b); and the aggregation of soot particle (c). the internal surface of the exhaust pipe; they collide to produce larger particles that eventually agglomerate to produce aggregates of soot.

\subsection{Fourier Transform Infrared Spectroscopy (FTIR)}

Spectra of soot samples were obtained from FTIR analysis. Figure 3 shows the peaks observed in the region between $4000 \mathrm{~cm}^{-1}$ and $600 \mathrm{~cm}^{-1}$. The peaks and their corresponding assignments are given in Table 1 . The strong peaks at $3857 \mathrm{~cm}^{-1}$ and $3711 \mathrm{~cm}^{-1}$ correspond to the residual $\mathrm{O}-\mathrm{H}$ surface groups present in the soot char [28], while the presence of the N-H stretching band is shown by the peak at $3402 \mathrm{~cm}^{-1}$ [29]. The peak at $2978 \mathrm{~cm}^{-1}$ is assigned to the $\mathrm{CH}$ stretching vibrations of the $\mathrm{CH}_{3}$ group [30,31]. The small peaks at $2754 \mathrm{~cm}^{-1}$ and $2492 \mathrm{~cm}^{-1}$ correspond to the aldehyde (-CHO) and thiol (S-H), respectively $[32,33]$. The possible functional group of the peak detected at 2283 $\mathrm{cm}^{-1}$ has not been previously reported, as noted by Matthews [34]. The $\mathrm{C}=\mathrm{O}$ stretching of carboxylic acids can be observed at $1720 \mathrm{~cm}^{-1}$ [35], while the peak at $1512 \mathrm{~cm}^{-1}$ corresponds to the $\mathrm{C}=\mathrm{C}$ stretching of aromatic or alkene groups [22]. A broadening is observed in the region of $1000-1300 \mathrm{~cm}^{-1}$ in the spectrum. This region is a complex section of the IR spectrum, where aromatic $\mathrm{C}-\mathrm{C}$ and $\mathrm{C}-\mathrm{H}$ plane deformation structures are observed; however, the most important structure corresponds to ether C-O-C stretching groups $[22,36]$. The peak at $1273 \mathrm{~cm}^{-1}$ corresponds to the $\mathrm{C}-\mathrm{O}$ stretch vibrations of carboxylic acids and ethers [37]. The small peak at $1010 \mathrm{~cm}^{-1}$ corresponds to the unsaturated hydroxyl (C-C-O) stretch [35], while the 


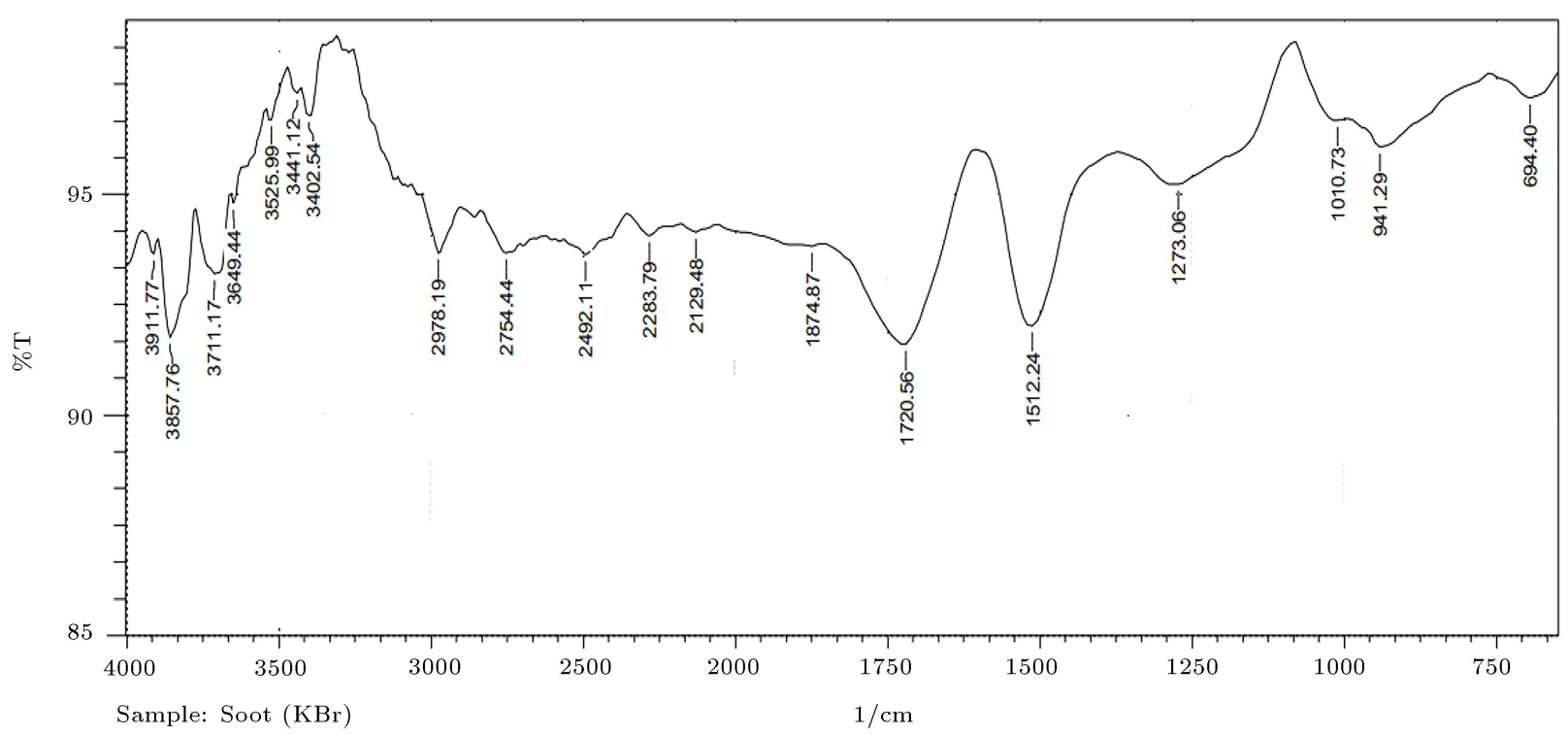

Figure 3. IR spectra of biomass soot.

Table 1. Peak assignments.

\begin{tabular}{lll}
\hline Peaks $\left.\mathbf{( c m}^{-\mathbf{1}}\right)$ & Assignment & Reference (s) \\
\hline 3857 (sharp) & O-H (hydroxyl) & {$[28]$} \\
3711 (sharp) & O-H & {$[67]$} \\
3402 & N-H & {$[29,68]$} \\
2978 & C-H & {$[30,31]$} \\
2754 & -CHO (aldehyde) & {$[33]$} \\
2492 & S-H (thiol) & {$[32]$} \\
2283 & Possible functional group could not be identified \\
1720 & C=O (carbonyl) & {$[35,69]$} \\
1512 & C=C (aromatic) & {$[22]$} \\
1273 (broad) & C-O & {$[37]$} \\
941 & P-OH & {$[38]$} \\
694 (broad) & C-H (out of plane deformations) & {$[39]$} \\
\hline
\end{tabular}

origin of the peak at $941 \mathrm{~cm}^{-1}$ corresponds to the phosphonic group [38]. The peak observed at $694 \mathrm{~cm}^{-1}$ corresponds to the $\mathrm{CH}$ out of plane deformations [39]. The FTIR analysis confirms the presence of carbon, oxygen, nitrogen, sulphur, hydrogen, and phosphorus.

\subsection{Scanning Electron Microscopy with Energy Dispersion Spectroscopy ( $S E M-E D S$ )}

Tables 2 and 3 give the elemental analysis of the soot char with and without inclusion of carbon/oxygen/nitrogen, respectively. The percentage of carbon is not included in Table 2 to best illustrate hetero-element concentrations. The tables quantitatively confirm the presence of some elements earlier observed from the FTIR analysis. The data from Tables 2 and 3 are plotted in Figures 2 and 3, respectively.
Table 2. Elemental analysis (carbon included).

\begin{tabular}{lc}
\hline Element name & $\begin{array}{c}\text { Weight } \\
\text { concentration (\%) }\end{array}$ \\
\hline Carbon & 75.05 \\
Oxygen & 15.13 \\
Iron & 2.92 \\
Nitrogen & 2.25 \\
Copper & 0.76 \\
Aluminium & 0.51 \\
Calcium & 0.48 \\
Sulphur & 0.48 \\
Potassium & 0.47 \\
Magnesium & 0.47 \\
Silicon & 0.42 \\
Phosphorus & 0.41 \\
Sodium & 0.38 \\
Manganese & 0.28 \\
\hline
\end{tabular}


Table 3. Elemental analysis (carbon excluded).

\begin{tabular}{lc}
\hline Element name & $\begin{array}{c}\text { Weight } \\
\text { concentration }\end{array}$ \\
\hline Iron & 32.65 \\
Aluminium & 8.54 \\
Copper & 8.48 \\
Magnesium & 7.98 \\
Silicon & 7.25 \\
Sulphur & 7.22 \\
Phosphorus & 6.55 \\
Sodium & 6.19 \\
Potassium & 6.00 \\
Calcium & 5.99 \\
Manganese & 3.15 \\
\hline
\end{tabular}

From Table 2, it can be seen that the elemental carbon content of the soot was found to be $75.05 \%$ carbon with $15.13 \%$ oxygen with the carbon content greater than biochar obtained from other biomass like rice, bamboo [40], and date palm [41].

The exclusion of carbon in the elemental analysis enhanced the presence of the elements earlier observed in the carbon inclusive analysis. The carbon rich soot can serve as a favorable adsorbent for nonbiodegradable or inorganic pollutants [42]. The oxygen content and oxygen-containing functional groups enhance the adsorption of organic pollutants by interacting with the pollutants via hydrogen bonding or complexation [43]. The addition of the carbon soot to soils combined with bioenergy can be used as a means to mitigate climate change [44]. The soot can also be explored as a binder-free electrode material for high performance energy storage devices such as super capacitors [45-47]. Iron, which is the most abundant element in addition to carbon and oxygen, increases the adsorption capacity in pollutant removal and toxicity reduction $[48,49]$.

As previously applied with diesel soot $[50,51]$, the obtained soot char can also be considered for use as an additive to lubricating oils to reduce the friction and wear rate reduction. In this respect, it could serve as an alternative to the use of diesel soot and carbon black as lubricant additives. Dispersion of soot nanoparticles to lubricating oils in small concentrations strengthens the anti-friction effects of the lubricants [50,52]; however, this depends on the oil formulation [51]. Soot can also be used as a solid lubricant [53,54].

The SEM analysis of the soot materials is shown in Figure 4 with a magnification ranging from 500 to 1500 times. The images show that the soot has a hollow morphology and a lustrous appearance with large surface particles. Moreover, there is no cluster formation because of the inherent stability of the

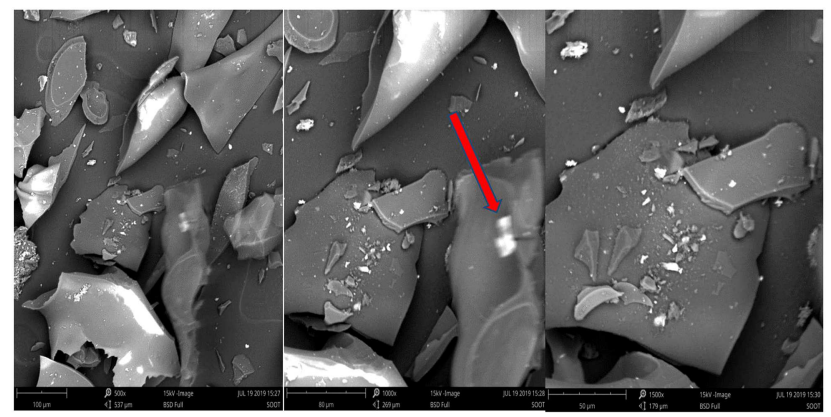

Figure 4. SEM micrographs of the biomass soot.

Table 4. Surface properties of the soot.

\begin{tabular}{ll}
\hline \multicolumn{1}{c}{ Parameter } & Value \\
\hline Multipoint BET surface area & $500.8 \mathrm{~m}^{2} / \mathrm{g}$ \\
Pore volume & $0.218 \mathrm{~cm}^{3} / \mathrm{g}$ \\
Pore diameter & $2.113 \mathrm{~nm}$ \\
\hline
\end{tabular}

soot [21]; there are white tiny grit grains/spheres (red arrow) commonly referred to as carbon nanospheres [22] on the surface, affirming the large surface area as confirmed by the BET analysis results.

\subsection{BET analysis}

The surface area, pore volume, and pore diameter of the soot char were analyzed using a BET analyzer, and the results obtained are presented in Table 4 below. The BET specific surface area of the soot was measured to be $500 \mathrm{~m}^{2} / \mathrm{g}$, while the $\mathrm{BJH}$ pore volume and pore diameter were measured to be 0.218 $\mathrm{cm}^{3} / \mathrm{g}$ and $2.113 \mathrm{~nm}$, respectively. The surface area and pore of the soot were found relatively higher than bio-chars previously obtained from the carbonization unit $[14,16]$, which is the main product. The specific surface area was also found to be higher than candle soot [55], diesel soot [56], and functionalized carbon soot [57], which possessed surface areas of $78.6 \mathrm{~m}^{2} / \mathrm{g}$, $55 \mathrm{~m}^{2} / \mathrm{g}$, and $137.93 \mathrm{~m}^{2} / \mathrm{g}$, respectively. High surface area increases the potential of the soot as -an adsorbent for heavy metals $[58,59]$ and other wastewater pollutants [60-62]. The pore size distribution is shown in Figure 5. It is observed that a significant volume of the soot has a pore size/diameter of $2-6 \mathrm{~nm}$. It is in the mesoporous range according to the International Union of Pure and Applied Chemistry (IUPAC) classification. This reveals that the soot obtained from the process is mesoporous in nature. The soot properties also make it a potential alternative to carbon black as a filler/additive to plastic composites [63,64], polymers, thermoplastic, and rubber blends $[65,66]$.

\section{Conclusion}

A significant agglomerative accumulation of fine soot char was observed to be trapped in the inner sections 


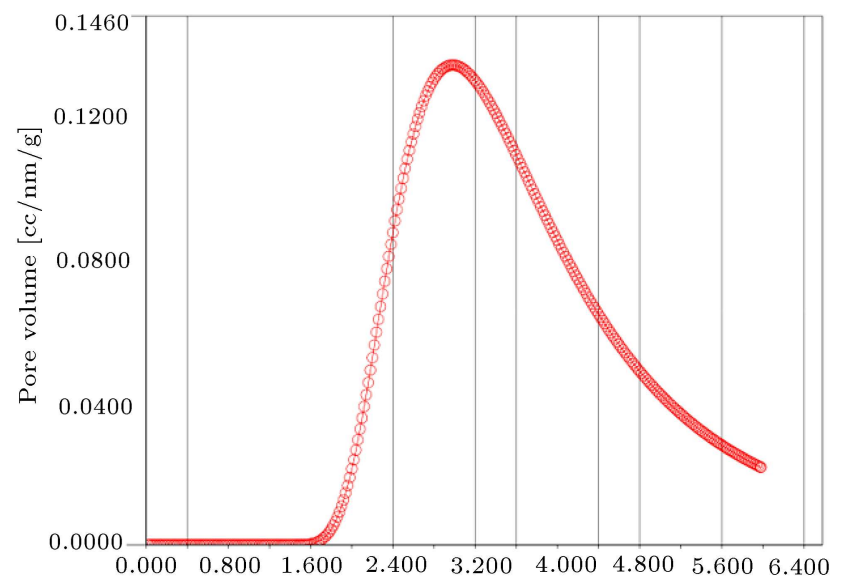

Figure 5. Pore size distribution of the soot obtained.

of the exhaust. In this paper, the soot derived from the experimentations in Adeniyi et al. $[14,16]$ was evaluated to understand its nature and qualities. FTIR analysis revealed the presence of hydroxyl, aromatic double bond, aldehyde, thiol, and carbonyl functional groups. EDS analysis revealed that the elemental carbon content of the soot was found to be $75.05 \%$ carbon with $15.13 \%$ oxygen. SEM analysis revealed that the soot had a hollow morphology and a lustrous appearance with white tiny grit grains of carbon nano-spheres. The Branueur-Emmett-Teller (BET) analysis revealed that the specific surface area of the soot was $500 \mathrm{~m}^{2} / \mathrm{g}$, while the pore volume and pore diameter were measured to be $0.218 \mathrm{cc} / \mathrm{g}$ and $2.113 \mathrm{~nm}$, respectively. The very high carbon content and surface area imply that it can serve as an adsorbent for water purification purpose. It can be considered for use as an additive to lubricating oils to reduce the friction and wear rate reduction, serving as an alternative to the use of diesel soot and carbon black as a lubricant additive.

\section{References}

1. Goyal, H., Seal, D., and Saxena, R. "Bio-fuels from thermochemical conversion of renewable resources: a review", Renewable and Sustainable Energy Reviews, 12(2), pp. 504-517 (2008).

2. Adeniyi, A.G. and Ighalo, J.O. "A review of steam reforming of glycerol", Chemical Papers, 73(11), pp. 2619-2635 (2019).

3. Adeniyi, A.G., Otoikhian, K.S., and Ighalo, J.O. "Steam reforming of biomass pyrolysis oil: A review", International Journal of Chemical Reactor Engineering, 73(11), pp. 2619-2635 (2019).

4. Azlina, W.A., Moghadam, R.A., Salleh, M.A.M., et al. "Air gasification of agricultural waste in a fluidized bed gasifier", World Review of Science, Technology and Sustainable Development, 8(2), pp. 100-113 (2011).

5. Bulushev, D.A. and Ross, J.R. "Catalysis for conver- sion of biomass to fuels via pyrolysis and gasification: a review", Catalysis Today, 171(1), pp. 1-13 (2011).

6. Carrascosa, M.S. "Reactor design and characterization of biochar", University of Agder (2016).

7. Doilov, S.K., Efimov, V.M., Ioonas, R.E., et al., Furnace for Thermal Processing of Lump Solid Fuel, Google Patents (1977).

8. Panwar, N., Kothari, R., and Tyagi, V. "Thermo chemical conversion of biomass-Eco friendly energy routes", Renewable and Sustainable Energy Reviews, 16(4), pp. 1801-1816 (2012).

9. James, A.M., Yuan, W., Boyette, M.D., et al. "Airflow and insulation effects on simultaneous syngas and biochar production in a top-lit updraft biomass gasifier", Renewable Energy, 117, pp. 116-124 (2018).

10. Chawdhury, M.A. and Mahkamov, K. "Development of a small downdraft biomass gasifier for developing countries", J. Sci. Res, 3(1), pp. 51-64 (2011).

11. Chee, C.S. "The air gasification of wood chips in a downdraft gasifier", Kansas State University (1987).

12. Olgun, H., Ozdogan, S., and Yinesor, G. "Results with a bench scale downdraft biomass gasifier for agricultural and forestry residues", Biomass and Bioenergy, 35(1), pp. 572-580 (2011).

13. Zainal, Z., Rifau, A., Quadir, G., et al. "Experimental investigation of a downdraft biomass gasifier", Biomass and Bioenergy, 23(4), pp. 283-289 (2002).

14. Adeniyi, A.G., Ighalo, J.O., and Onifade, D.V. "Production of biochar from elephant grass (Pernisetum purpureum) using an updraft biomass gasifier with retort heating", Biofuels, 12, pp. 1-8 (2019).

15. Adeniyi, A., Ighalo, J., Onifade, D., et al. "Production of hybrid biochar by retort-heating of elephant grass (Pennisetum Purpureum) and Low Density Polyethylene (LDPE) for waste management and product development", Biofuel, 12(10), Taylor and Francis (2021).

16. Adeniyi, A.G., Ighalo, J.O., and Onifade, D.V. "Production of bio-char from plantain (musa paradisiaca) fibers using an updraft biomass gasifier with retort heating", Combustion Science and Technology, 193(1), pp. 60-74 (2019).

17. Adeniyi, A.G., Ighalo, J.O., and Onifade, D.V. "Biochar from the thermochemical conversion of orange (Citrus sinensis) peel and Albedo: product quality and potential applications", Chemistry Africa, 3(2), pp. 439-448 (2020).

18. Ighalo, J.O., Onifade, D.V., and Adeniyi, A.G. "Retort-heating carbonisation of almond (Terminalia catappa) leaves and LDPE waste for biochar production: evaluation of product quality", Chemistry Africa, International Journal of Sustainable Engineering, 3(2), pp. 439-448 (2021).

19. Adeniyi, A.G., Abdulkareem, S.A., Ighalo, J.O., et al. "Thermochemical Co-conversion of sugarcane bagasseLDPE hybrid waste into biochar", Arabian Journal for Science and Engineering, 46(7), pp. 6391-6397 (2020). 
20. Adelodun, A.A., Adeniyi, A.G., Ighalo, J.O., et al. "Thermochemical conversion of oil palm Fiber-LDPE hybrid waste into biochar", Biofuels, Bioproducts and Biorefining, 14(6), pp. 1313-1323 (2020).

21. Sarkar, I., Raman, R., Jayanth, K., et al. "Characterization of Soot microstructure for diesel and biodiesel using diesel particulate filter", U.C.e.a. (Ed.) Innovative Design, Analysis and Development Practices in Aerospace and Automotive Engineering, Springer (2019).

22. Manoj, B., Sreelaksmi, S., Mohan, A.N., et al. "Characterization of diesel Soot from the combustion in engine by X-ray and spectroscopic techniques", International Journal of Electrochemical Science, 7, pp. 3215-3221 (2012).

23. Kowthaman, C.N. and Arul Mozhi Selvan, V. "Synthesis and characterization of carbon nanotubes from engine soot and its application as an additive in schizochytrium biodiesel fuelled DICI engine", Energy Reports, 6, pp. 2126-2139 (2020).

24. Atiku, F.A., Mitchell, E.J.S., Lea-Langton, A.R., et al. "The impact of fuel properties on the composition of soot produced by the combustion of residential solid fuels in a domestic stove", Fuel Processing Technology, 151, pp. 117-125 (2016).

25. Knauer, M., Carrara, M., Rothe, D., et al. "Changes in structure and reactivity of soot during oxidation and gasification by oxygen, studied by micro-Raman spectroscopy and temperature programmed oxidation", Aerosol Science and Technology, 43(1), pp. 1-8 (2009).

26. Qin, K., Jensen, P.A., Lin, W., et al. "Biomass gasification behavior in an entrained flow reactor: gas product distribution and soot formation", Energy \& Fuels, 26(9), pp. 5992-6002 (2012).

27. Kowthaman, C.N. and Arul Mozhi Selvan, V. "Waste to green fuels: Kinetic study of low lipid waste algae for energy development", Bioresource Technology Reports, 11, p. 100510 (2020).

28. Ignatov, S., Sennikov, P., Razuvaev, A., and Chuprov, L. "Binary molecular complexes of silicon tetrafluoride with water, methanol, and dimethyl ether. Quantumchemical study", Russian Chemical Bulletin, 50(12), pp. 2316-2324 (2001).

29. Ramachandran, S., Nandhakumar, S., and DhanaRaju, M.D. "Development and in vitro evaluation of biodegradable chitosan microspheres loaded with ranitidine and cross linked with glutaraldehyde", Int. J. Pharm. Tech. Res, 1, pp. 488-496 (2011).

30. Lal, V., Khalizov, A.F., Lin, Y., et al. "Heterogeneous reactions of epoxides in acidic media", The Journal of Physical Chemistry A, 116(24), pp. 6078-6090 (2012).

31. Thirunavukkuarasu, K. "Carbon nanostructures under high pressure studied by infrared spectroscopy", $\mathrm{PhD}$ Thesis, Mathematisch-Naturwissenschaftlichen Fakultät, Universität Augsburg (2009).

32. Thomas, M.J. and Judes, J. "Development and characterization of metal-dopant-based zirconia via an electrospinning process for scientific applications", $M a$ teriali in Tehnologije, 52(6), pp. 751-761 (2018).

33. Zhang, Y., Zhu, T., Fang, Y., et al. "Carbonarones $\mathrm{A}$ and $\mathrm{B}$, new bioactive $\gamma$-pyrone and $\alpha$-pyridone derivatives from the marine-derived fungus Aspergillus carbonarius", The Journal of Antibiotics, 60(2), p. 153 (2007).

34. Matthews, S. "Structural changes of rice straw pretreated with Paenibacillus and Aspergillus fumigatus", International Journal of Agricultural and Food Research, 5(4), pp. 1-7 (2016).

35. Cain, J.P., Gassman, P.L., Wang, H., et al. "MicroFTIR study of soot chemical composition-evidence of aliphatic hydrocarbons on nascent soot surfaces", Physical Chemistry Chemical Physics, 12(20), pp. 5206-5218 (2010).

36. Mohan, A.N. and Manoj, B. "Synthesis and characterization of carbon nanospheres from hydrocarbon soot", Int. J. Electrochem. Sci, 7(10), pp. 9537-9549 (2012).

37. Bladt, H., Schmid, J., Kireeva, E.D., et al. "Impact of $\mathrm{Fe}$ content in laboratory-produced soot aerosol on its composition, structure, and thermo-chemical properties", Aerosol Science and Technology, 46(12), pp. 1337-1348 (2012).

38. Zenobi, M.C., Luengo, C.V., Avena, M.J., et al. "An ATR-FTIR study of different phosphonic acids adsorbed onto boehmite", Spectrochimica Acta Part A: Molecular and Biomolecular Spectroscopy, 75(4), pp. 1283-1288 (2010).

39. Ramachandran, E. and Natarajan, S. "XRD, thermal and FTIR studies on gel grown DL-Phenylalanine crystals", Crystal Research and Technology: Journal of Experimental and Industrial Crystallography, 42(6), pp. 617-620 (2007).

40. Qu, X., Fu, H., Mao, J., et al. "Chemical and structural properties of dissolved black carbon released from biochars", Carbon, 96, pp. 759-767 (2016).

41. Usman, A.R., Abduljabbar, A., Vithanage, M., et al. "Biochar production from date palm waste: charring temperature induced changes in composition and surface chemistry", Journal of Analytical and Applied Pyrolysis, 115, pp. 392-400 (2015).

42. Liu, P., Liu, W.-J., Jiang, H., et al. "Modification of bio-char derived from fast pyrolysis of biomass and its application in removal of tetracycline from aqueous solution", Bioresource Technology, 121, pp. 235-240 (2012).

43. Liu, W.-J., Zeng, F.-X., Jiang, H., et al. "Preparation of high adsorption capacity bio-chars from waste biomass", Bioresource Technology, 102(17), pp. 82478252 (2011).

44. Keiluweit, M., Nico, P.S., Johnson, M.G., et al. "Dynamic molecular structure of plant biomass-derived black carbon (biochar)", Environmental Science \& Technology, 44(4), pp. 1247-1253 (2010). 
45. He, S. and Chen, W. "Application of biomass-derived flexible carbon cloth coated with $\mathrm{MnO}_{2}$ nanosheets in supercapacitors", Journal of Power Sources, 294, pp. 150-158 (2015).

46. Ling, Z., Wang, Z., Zhang, M., et al. "Sustainable synthesis and assembly of biomass-derived B/N codoped carbon nanosheets with ultrahigh aspect ratio for high-performance supercapacitors", Advanced Functional Materials, 26(1), pp. 111-119 (2016).

47. Bello, A., Manyala, N., Barzegar, F., et al. "Renewable pine cone biomass derived carbon materials for supercapacitor application", Rsc Advances, 6(3), pp. 1800-1809 (2016).

48. Kim, J., Song, J., Lee, S.-M., et al. "Application of iron-modified biochar for arsenite removal and toxicity reduction", Journal of Industrial and Engineering Chemistry, 80, pp. 17-22 (2019).

49. Wang, P., Tang, L., Wei, X., et al. "Synthesis and application of iron and zinc doped biochar for removal of p-nitrophenol in wastewater and assessment of the influence of co-existed $\mathrm{Pb}$ (II)", Applied Surface Science, 392, pp. 391-401 (2017).

50. Guo, M.-F., Cai, Z.-B., Zhang, Z.-C., et al. "Characterization and lubrication performance of diesel soot nanoparticles as oil lubricant additives", $R S C A d$ vances, 5(123), pp. 101965-101974 (2015).

51. Hu, E., Hu, X., Liu, T., et al. "The role of soot particles in the tribological behavior of engine lubricating oils", Wear, 304(1-2), pp. 152-161 (2013).

52. George, S., Balla, S., and Gautam, M. "Effect of diesel soot contaminated oil on engine wear", Wear, 262(910), pp. 1113-1122 (2007).

53. Chuan, L., Hui, S., Jun, Z., et al. "Novel approach for improved tribological behavior of biodiesel soot in liquid paraffin", China Petroleum Processing \& Petrochemical Technology, 21(1), pp. 101-109 (2019).

54. Li, C., Li, M., Wang, X., et al. "Novel carbon nanoparticles derived from biodiesel soot as lubricant additives", Nanomaterials, 9(8), p. 1115 (2019).

55. Kakunuri, M. and Sharma, C.S. "Candle soot derived fractal-like carbon nanoparticles network as high-rate lithium ion battery anode material", Electrochimica Acta, 180, pp. 353-359 (2015).

56. Growney, D.J., Mykhaylyk, O.O., Middlemiss, L., et al. "Is carbon black a suitable model colloidal substrate for diesel soot?", Langmuir, 31(38), pp. 10358-10369 (2015).

57. Raj, C.J., Kim, B.C., Cho, B.-B., et al. "Electrochemical supercapacitor behaviour of functionalized candle flame carbon soot", Bulletin of Materials Science, 39(1), pp. 241-248 (2016).

58. Ighalo, J.O., Adeniyi, A.G., Eletta, O.A.A., et al. "Competitive Adsorption of $\mathrm{Pb}(\mathrm{II}), \mathrm{Cu}(\mathrm{II}), \mathrm{Fe}(\mathrm{II})$ and $\mathrm{Zn}(\mathrm{II})$ from Aqueous Media Using Biochar from Oil Palm (Elaeis guineensis) Fibers: A Kinetic and Equilibrium Study", Indian Chemical Engineer, pp. 111 (2020).
59. Ighalo, J.O., Arowoyele, L.T., Ogunniyi, S., et al. "Utilisation of biomass and hybrid biochar from elephant grass and low density polyethylene for the competitive adsorption of $\mathrm{Pb}(\mathrm{II}), \mathrm{Cu}(\mathrm{II}), \mathrm{Fe}(\mathrm{II})$ and $\mathrm{Zn}(\mathrm{II})$ from aqueous media", Recent Innovations in Chemical Engineering, 13, pp. 1-11 (2020).

60. Trubetskaya, A., Kling, J., Ershag, O., et al. "Removal of phenol and chlorine from wastewater using steam activated biomass soot and tire carbon black", Journal of Hazardous Materials, 365, pp. 846-856 (2019).

61. Ighalo, J.O., Ajala, O.J., Adeniyi, A.G., et al. "Ecotoxicology of glyphosate and recent advances in its mitigation by adsorption", Environmental Science and Pollution Research, 28(3), pp. 2655-2668 (2021).

62. Oba, S.N., Ighalo, J.O., Aniagor, C.O., et al. "Removal of ibuprofen from aqueous media by adsorption: A comprehensive review", Science of the Total Eanvironment, 780, 146608 (2021).

63. Onifade, D.V., Ighalo, J.O., Adeniyi, A.G., et al. "Morphological and thermal properties of polystyrene composite reinforced with biochar from plantain stalk fibre", Materials International, 2(2), pp. 150-156 (2020).

64. Adeniyi, A.G., Abdulkareem, S.A., Ighalo, J.O., et al. "Morphological and thermal properties of polystyrene composite reinforced with biochar from elephant grass (Pennisetum purpureum)", Journal of Thermoplastic Composite Materials, pp. 1-16 (2020).

65. Mathew, T., Dierkes, W.K., Talma, A., et al. "Carbon particles coated with polymer films, methods for their production and uses thereof", Google Patents (2016).

66. Otoikhian, K.S., Adeniyi, A.G., Dada, A.M., et al. "Assessment of carbonised wood-flour fillers on the mechanical properties of natural rubber vulcanisates", European Journal of Sustainable Development Research, 3(4), pp. 1-10 (2019).

67. Patai, S., The Chemistry of Peroxides, John Wiley \& Sons (2015).

68. Hesari, Z., Shirkavand Hadavand, B., and Mahmoodi Hashemi, M. "Fabrication and study of structural, optical and electrical properties of UV curable conductive polyurethane acrylate films containing polyaniline$\mathrm{Co}_{3} \mathrm{O}_{4}$ nanocomposites", Progress in Color, Colorants and Coatings, 9(1), pp. 41-52 (2016).

69. Sahoo, B.N. and Kandasubramanian, B. "Photoluminescent carbon soot particles derived from controlled combustion of camphor for superhydrophobic applications", RSC Advances, 4(22), pp. 11331-11342 (2014).

\section{Biographies}

Adewale George Adeniyi is a Senior Lecturer at the Department of Chemical Engineering, University of Ilorin, Nigeria. He holds a PhD in Chemical Engineering from Ladoke Akintola University of Technology, Ogbomoso, Nigeria. He is interested in process and product development with a focus on computer-aided 
modeling and the optimization of chemical process systems, biofuel production, and solid waste recycling.

Damilola Victoria Onifade has a BSc degree in Chemical Engineering and obtained in 2015 from Ladoke Akintola University of Technology, Ogbomoso, Nigeria. She also holds a MSc degree in Chemical Engineering in 2020 from the University of Ilorin, Nigeria. Her research interests include solid waste management, chemical process optimization, computer-aided model- ing and design, biofuels, and product development.

Joshua O. Ighalo obtained his BSc degree in Chemical Engineering in 2015 from the University of Benin, Nigeria. He also obtained a MSc degree in Chemical Engineering in 2020 from the University of Ilorin, Nigeria. His research interests include computeraided modeling and optimization of chemical process systems, biofuel production, solid waste management, and environmental pollution control. 